\section{The Onset of Habituation Effects}

\section{Predicting Fluctuations in News Use During the COVID-19 Pandemic by Disease Occurrence}

DOI: $10.47368 /$ ejhc.2021.303 2021, Vol. 2(3) 44-61

CC BY 4.0

\author{
Viorela Dan (D), Hans-Bernd Brosius \\ Department of Media and Communication, LMU Munich, Germany
}

\begin{abstract}
While extraordinary events like pandemics may prompt an increase in information-seeking behaviour, such trends are unlikely to be sustainable. Over time, issue fatigue/overdose is expected to set in. This study employed generalised additive mixed models (GAMMs) to determine whether attention to TV news corresponded with real-world developments. We sought to predict news use in Germany during the first wave of the COVID-19 pandemic based on disease occurrence next to two well-established predictors of news use (total TV use and day of the week). The association of key events with news use was also assessed. Initially, news use increased with disease occurrence. However, as the pandemic progressed, the linkage between the two variables weakened considerably, suggesting the onset of a habituation effect. Some support emerged for the idea that key events increased news use. Overall, our results are more in line with the explanation provided by agenda-setting theory and various information-seeking models than with the notion of coping through information avoidance. Thus, how the pandemic progresses appears to be a good predictor of news use at the aggregate level, although its predictive power decreases over time.
\end{abstract}

\title{
Keywords
}

Media use, information avoidance, issue fatigue, need for orientation

As pandemics often disrupt the normal course of life, affected people can exhibit an anxious response to these events (World Health Organization [WHO], 2007). Two antipodal mechanisms for coping with this anxiety have been described. One is information seeking, involving an attempt to improve one's state of knowledge about the issue at hand by searching for and using additional 
information (Li, 2007; Spence et al., 2008). The other is information avoidance, that is, the effort to stonewall information about the anxiety-raising issue (Brashers et al., 2000; Kuhlmann et al., 2014). Importantly, public attention to issues - pandemics included — may be best described as characterised by ups and downs. Thus, phases in which people turn their attention to issues (information seeking) alternate with those in which they divert their attention away from them (information avoidance; Downs, 1972; Geiß, 2011; Mazur, 1998).

Given the importance of information provision during a pandemic - as knowledge of preventive measures predicts their implementation (Liu, 2020; Voeten et al., 2009) - this study sought to retrace these phenomena. The focus was on top evening TV newscasts in Germany, two public and two private. TV remains Germans' preferred news source, with $72 \%$ stating that they had watched news on TV during the last week (Hölig \& Hasebrink, 2019; see also Breunig et al., 2020). Indeed, traditional news sources (i.e., TV, radio, print) are still being used preferentially in Germany (83\%), more so than news on the internet (68\%, Hölig \& Hasebrink, 2019; see also Emmer et al., 2002).

We present a series of analyses using generalised additive mixed models (GAMMs) to determine whether news use during the first six months of the COVID-19 pandemic (used as an indicator for public attention) corresponded to disease occurrence, thus the daily number of new confirmed cases of COVID-19 (used as a real-world indicator of problem severity). The influence levels of two well-established predictors of news use - total TV use and the day of the weekwere also accounted for. Additional analyses were conducted to reveal linkages to past news use figures and key events (i.e., the announcement of the social-distancing policy). The analyses revealed that disease occurrence predicted fluctuations in news use but only to a certain point, suggesting the onset of a habituation effect.

The type of research reported here matters for two main reasons. First, from a public health perspective, the need to provide citizens with accurate and timely information on prevention and treatment increases as a health crisis becomes more severe. In the case of a pandemic, for instance, public health officials are likely to organise press conferences, issue press releases, and so on, to increase the chances that journalists pick up the information conveyed. For this information to unfold its potential, it is necessary that people actually attend to it, for instance by watching their preferred evening newscast. In principle then, public attention to news should increase as the health crisis aggravates. Ideally, knowledge of preventive measures and treatment options would arise out of news consumption, which should increase the likelihood that these measures are actually being implemented. In this way, news use could then help overcome a health crisis and yield positive public health outcomes.

Yet, the more-more logic - according to which the worse a crisis becomes, the more people will want to know about it - may be oversimplifying. The study presented here thus matters for a second reason: It advances our understanding of people's need for information. Is the total amount of public attention infinite? If not, when is the maximum amount of attention reached? And when do real-world indicators of problem severity become dissociated from public attention? To the best of our knowledge, this study is the first one to quantify precisely when issue fatigue/overdose sets in. This allows us to get one step closer to understanding people's information needs in times of crisis. 


\section{Disease Occurrence and Seeking/Avoiding Information}

Previous studies described several ways in which people confronted with a crisis behave with a view to gaining a sense of control. Much of the available research has identified information seeking, the search for and use of additional information, as an efficient coping mechanism (Spence et al., 2008). Over the years, numerous models for information seeking have been proposed, most notably the Risk Information Seeking and Processing (RISP) model (Griffin et al., 1999) and the Planned Risk Information Seeking Model (PRISM; Kahlor, 2010). The RISP model proposes a comprehensive explanation to why people may seek information in the event of a risk. The following were proposed as main contributors to this decision: the belief that the information one has is insufficient (i.e. information insufficiency); trust in one's ability to seek and find relevant information (i.e., internal efficacy); and the belief that information sources provide the information needed (i.e. external efficacy). Individual differences were shown to moderate the effect of these characteristics on actual information seeking behaviour (e.g., whether people feel that others expect them to be informed about the topic; Griffin et al., 1999). The PRISM model builds on RISP and its precursors, and prioritises the individual-level variables associated with health risk information seeking. Next to information insufficiency, which already played a major role in the RISP model, this line of work also focused on beliefs about information seeking itself. Studies found that they impacted people's intention to engage in this type of behaviour (e.g. in the event of a positive result of cost and benefit analysis, see Kahlor, 2010).

Subsequent studies have served to cement the idea that negative emotions, such as anxiety and uncertainty - expected to rise in a crisis — predict information seeking (So et al., 2019; Tausczik et al., 2012). In journalism and media studies, agenda-setting theory also indicates that people's need for orientation in times of crisis prompts information seeking, and news use could satisfy this need (Matthes, 2005; McCombs, 2004). People were shown to experience an elevated need for orientation when the issue at hand was personally relevant to them and when they perceived that they had less information on that issue than needed. In a nutshell, the higher a person's need for orientation, the more likely it becomes that the person will seek information, for instance by using news. To illustrate, one study found that, as the number of patients rose in a swine flu epidemic, the amount of media attention also increased (Hilton \& Hunt, 2011; see also Kostkova et al., 2013). This suggests the following hypothesis:

H1: Fluctuations in disease occurrence will predict fluctuations in news use in that the viewership will increase as disease occurrence rates increase.

Should the hypothesised increase in news consumption occur, it may benefit certain outlets more than others. Indeed, as most authorities tend to prefer traditional media for the dissemination of updates and behavioural recommendations (Seeger, 2002), audiences turn to them in times of crisis (Walter et al., 2012). Specifically, TV news - our object of study - has been identified as one key source of information in extraordinary situations (te Poel et al., 2021; Viehmann, 2020; Wong \& Sam, 2010). This preference for well-tried media could also mean that public broadcasters would benefit more from the newly emerged need for orientation compared with their private counterparts. Indeed, in Germany, public broadcasters produce TV newscasts since the 1950s (ARD) and, respectively, 1960s (ZDF). Private broadcasters entered the market much later, in the 
mid-1980s (RTL, Sat.1; Krupp, 2020). Moreover, public broadcasters are generally believed to produce reports of higher quality and relevance than public broadcasters do (Breunig et al. 2020; Gehrke \& Hohlfeld, 1994; Köhler, 2006). We pose the following hypothesis:

H2: The ability of disease occurrence to predict news use (specified in H1) will be higher for public TV stations than for private ones.

An additional restriction to the relationship specified in $\mathrm{H} 1$ is in order here. Specifically, the linkage between disease occurrence and news use is unlikely to be constant. Indeed, as the disease occurrence increases, i.e. the number of confirmed cases (and so does the risk), some people's news use may decrease. Put differently, information avoidance may increase as people experience anxiety and helplessness, as proposed by the Uncertainty Management Theory (UMT) (Brashers et al., 2000) and the Extended Parallel Process Model (EPPM) (Witte, 1994). The UMT was the first theory to conceptualise uncertainty as neutral, rather than negative by default. In some cases, uncertainty can be a good thing; in others, it can be detrimental. To illustrate, not knowing one's life expectancy estimate after a terminal cancer diagnosis may allow people to live their lives more freely. In other situations, for instance when contagion with a severe disease can be prevented, not knowing how to do this (i.e. uncertainty) is likely to be perceived in a negative way (see Brashers et al., 2000). The EPPM explains how people react to situations that can be expected to induce fear, such as pandemics. In particular, it proposes that the following factors play a role: selfefficacy, response efficacy, susceptibility and severity. In short, this means that the response to fear-inducing events depends on whether a person feels that they are able to do what is needed to control the risk (e.g., wear a face mask); that the adopted measure will help achieve the goal envisioned (e.g., that wearing a face mask will considerably reduce the risk of contagion); whether the person believes that the threat will affect them personally; and also based on whether the risk is perceived as serious (i.e. risk magnitude).

In fact, ups and downs in levels of media/public attention to issues are common, prompting the proposal of an issue-attention cycle (Downs, 1972). In the words of Downs, "public attention rarely remains sharply focused upon any one issue for very long-even if it involves a continuing problem of crucial importance to society. Instead, ... [a problem] suddenly leaps into prominence, remains there for a short time, and then - though still largely unresolved-gradually fades from the center of public attention" (Downs, 1972, p. 38). Downs' observations have generated many subsequent studies, providing ample support for the idea of ups and downs in attentional levels (for a critical discussion, see Ungar, 1992).

Most research to date has focused on fluctuations in media attention (rather than in public attention). Taken together, the studies suggest that an issue becomes "stale" (Mazur, 1998, p. 469) within a few weeks and is replaced by others (Bento et al., 2020). Yet, staleness or issue fatigue is not a direct function of the severity of the problem; rather, it may be dissociated from it. Although the problem leading to the original attentional peak persists or even worsens (Geiß, 2011; Mazur, 1998), issue fatigue may arise when the frames that can be brought to the issue are exhausted and news sources contributing something new become scarce (Hawkins, 2011; Ungar, 2000; Vasterman, 2005). ${ }^{1}$ Public attention has been shown to fluctuate in a similar way to media attention. Instead of issue fatigue, some scholars have spoken of issue overdose when referring to why, in time, audiences avoid news on a certain topic (Kuhlmann et al., 2014). This occurs when 
the topic prompts negative attitudes, thoughts, or emotions, and additional news use on the topic is considered unnecessary or even detrimental to one's wellbeing (Geiß, 2015). Recent related studies conducted in other countries suggested a relationship between disease occurrence and information seeking but highlighted that such effects were rather short-lived, dropping to baseline within one to two weeks (Bento et al., 2020; Singh et al., 2020). Assuming issue overdose and/or habituation will eventually occur in the context of a pandemic, the following should hold true:

H3: The ability of disease occurrence to predict news use (specified in H1) will decrease over time.

From the above, it follows that, once the overdose stage is reached, it takes an extraordinary development to prompt "spasmodic recurrences of interest" (Downs, 1972, p. 39)—what Brosius and Eps (1995) called "key events" (p. 391). For instance, one study showed that earthquakes increased the level of attention to fracking (Opperhuizen \& Schouten, 2020). Another study revealed that similar mechanisms were at play in the media attention awarded to H1N1, which is more commonly known as the swine flu (Vasterman \& Ruigrok, 2013). Kostkova et al. (2013) reported an increase in health professionals' attention (but not in that of the general public) in accordance with public health events, the issue of policies, and the release of important documents. We posit the following:

H4: The ability of disease occurrence, total TV use, and day of the week to predict news use will decrease as the number of key events increases.

\section{Methods}

We used GAMMs in $\mathrm{R}$ to investigate whether news use (as an indicator of public attention) could be predicted by disease occurrence (as a real-world indicator of problem severity) next to two welltried predictors (total TV use and day of the week, see e.g., Klingler \& Turecek, 2019). The predictive power of total TV use is easily understood: When people are in front of their TVs (e.g., watching a football match), they are generally more likely to watch a newscast that happens to be broadcast (e.g., in the break between the first and second halves of the match). The predictive power of the day of the week can be explained with reference to people's daily routines, as they influence the time that they can, in principle, allocate to media use. For instance - as most people leave their homes for work early in the morning and only return in the evening - during the week, they can only watch TV late in the day. By contrast, over the weekend, most people have more free time and are thus more likely to allocate some of it to watching TV. Moreover, people might have more time for entertainment programming during the weekend, and take less time for news use (see Klingler \& Turecek, 2019).

Our approach was suitable because it had the potential to expose long-term trends in the dayby-day interaction between the four variables. In addition, descriptive statistics were employed to shed light on the influence of key events on news use. For context, descriptive statistics were also employed to illustrate disease occurrence in Germany, total TV use, and variations in news per broadcaster type in absolute figures and changes in percent from the previous year. 


\section{Data Collection}

News use data were obtained from a local public broadcaster that is part of the ARD consortium of public broadcasters in Germany. This broadcaster provided us with the daily viewing figures for the main evening newscasts in Germany for the period of January 1 to June 16 in both 2019 and 2020. Specifically, the following evening newscasts were included in the analysis: Tagesschau, heute, RTL aktuell, and Sat.1 Nachrichten. Total TV use data were obtained from the same source. The timeframe of 168 days each for 2019 and 2020 was set with the aim of including the first wave of the pandemic in Germany (March - April 2020) in addition to a similar number of days before and after this first wave.

Disease occurrence data were those provided by the WHO, John Hopkins University, and the Robert Koch Institute (RKI), the latter being the German equivalent of the US Centers for Disease Control and Prevention (CDC). These data covered the period from January 28, 2020 (when the first case was diagnosed) until June 16, 2020 (the date until which news use data were available).

\section{Measures}

Total TV use data was operationalised in minutes, thus the number of minutes people spent in front of their TVs each day. By contrast, news use was recorded in millions, i.e., the number of people who watched the news each day. Disease occurrence was operationalised as the number of people tested positive for the coronavirus on that day (i.e., new confirmed cases per day).

Key events were identified using an extensive retrospective online search drawing mainly on the RKI website, Google Trends, and an informal survey of mainstream media coverage during analysis. The goal was to identify game changers or extraordinary developments or aspects with the potential of generating extensive attention (see Brosius \& Eps, 1995). In the dataset, the presence of a key event was recorded using a yes/no variable for each day (coded as $1=$ present, $0=a b s e n t$ ) and specified in a string variable. In total, 52 developments in eight categories were identified as key events from a German perspective. The category "superspreader events" $(n=4)$ entailed extraordinary contagion waves, such as those in the Heinsberg area following carnival festivities. "Risk containment" $(n=19)$ was reserved for the announcement of measures, such as travel bans and social distancing. "Emergency aids" was used for measures to support the economy, the healthcare system, and the cultural and creative sectors $(n=6)$. The category "relaxing restrictions" $(n=15)$ included measures reinstating pre-pandemic normalcy, such as inperson teaching in schools. "Appeals to the population" $(n=2)$ was used for public addresses by the chancellor urging the population to take the pandemic seriously. The category "protests" $(n=3)$ was employed for large-scale events at which people vented about the risk containment measures or questioned the existence of the pandemic. Finally, the category "medical progress" $(n=3)$ was reserved for breakthroughs related to diagnosis, treatment, or prevention. A full list of key events can be obtained on request.

\section{Data Analysis}

Three GAMM analyses were computed as follows: one to predict total news use (public and private broadcasters together), one for use of public TV news only, and one for use of private TV news only. These predictions were made based on disease occurrence $(\mathrm{lag}=1)$, total TV use, and day 
of the week. These three measures were thus conceptualised as independent variables. The key assumption of GAMM is that effects are additive. Furthermore, it assumes that residuals (or error terms) are normally distributed, their variance is constant (homoskedasticity), and they are independent. GAMM allows the computation of linear and smooth functions. Accordingly, numeric covariables were predicted as smooth functions (semiparametric prediction). The day of the week entered the analysis as cyclical splines, meaning that the transition from the last day to the first day was equated. To account for this, Sundays were randomly coded as 0 or 7 . The timeseries structure of the data and the autocorrelation ${ }^{2}$ arising from it were accounted for through the assumption of the correlation structure as a continuous AR(1) process. Since there was no meaningful way to include key events in GAMM analyses, we used descriptive statistics for H4.

\section{Findings}

\section{Descriptive Statistics}

For context, we begin by presenting some key descriptive statistics before moving on to reporting the results of the hypothesis testing. It is worth noting that the first wave of the COVID-19 pandemic in Germany peaked between day 70 and day 100, resulting in a steep bell curve (Figure 1). Media use in general, including news and other types of programming, was subject to the usual fluctuations up to around day 70 and became more irregular thereafter (Figure 2). A similar pattern is revealed by news use, which appeared to peak at approximately the same time as the disease occurrence did. This is illustrated in Figure 3 (absolute figures) and Figure 4 (changes from news use in the previous year in percentages). Below, results of statistical procedures are reported that suggest that disease occurrence was a rather good predictor of news use during the first wave of the pandemic in Germany - next to the other two well-established factors of influence included in the analysis (i.e., total TV use and day of the week).

\section{Results of Hypothesis Testing}

$\mathrm{H} 1$, positing that fluctuations in disease occurrence would predict ups and downs in news use, was supported. As shown in Table 1 (first column) and Figure 5, disease occurrence statistics contributed to predicting news use beyond the two well-established factors of influence. ${ }^{3}$ Together, the three independent variables explained $81.3 \%$ of the variance in news use. Notably, news use increased as disease occurrence rates increased and decreased as disease occurrence statistics decreased. 


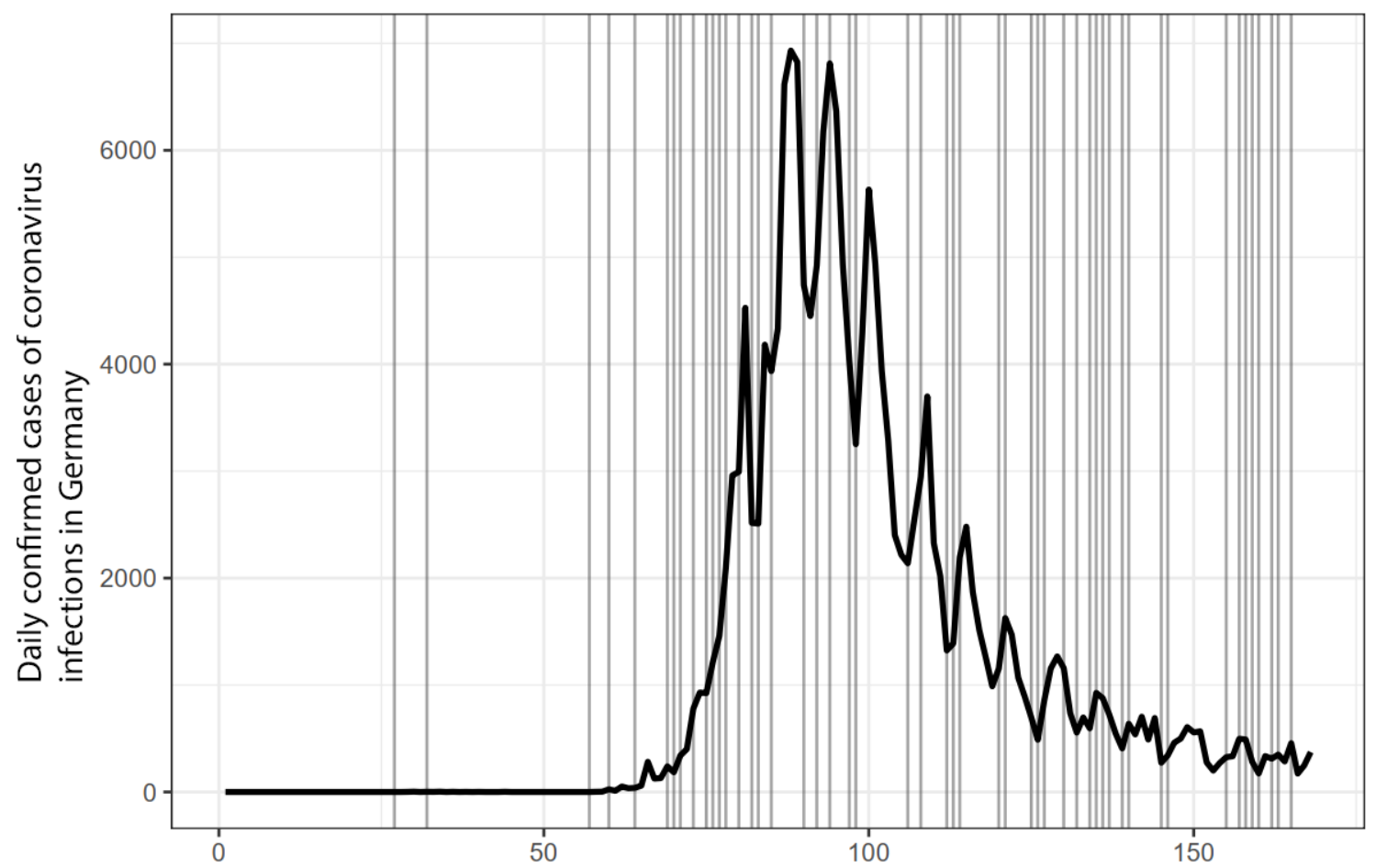

Figure 1. Disease Occurrence in Germany (First Wave of the COVID-19 Pandemic) Note. The grey vertical lines denote the presence of a key event on that day.

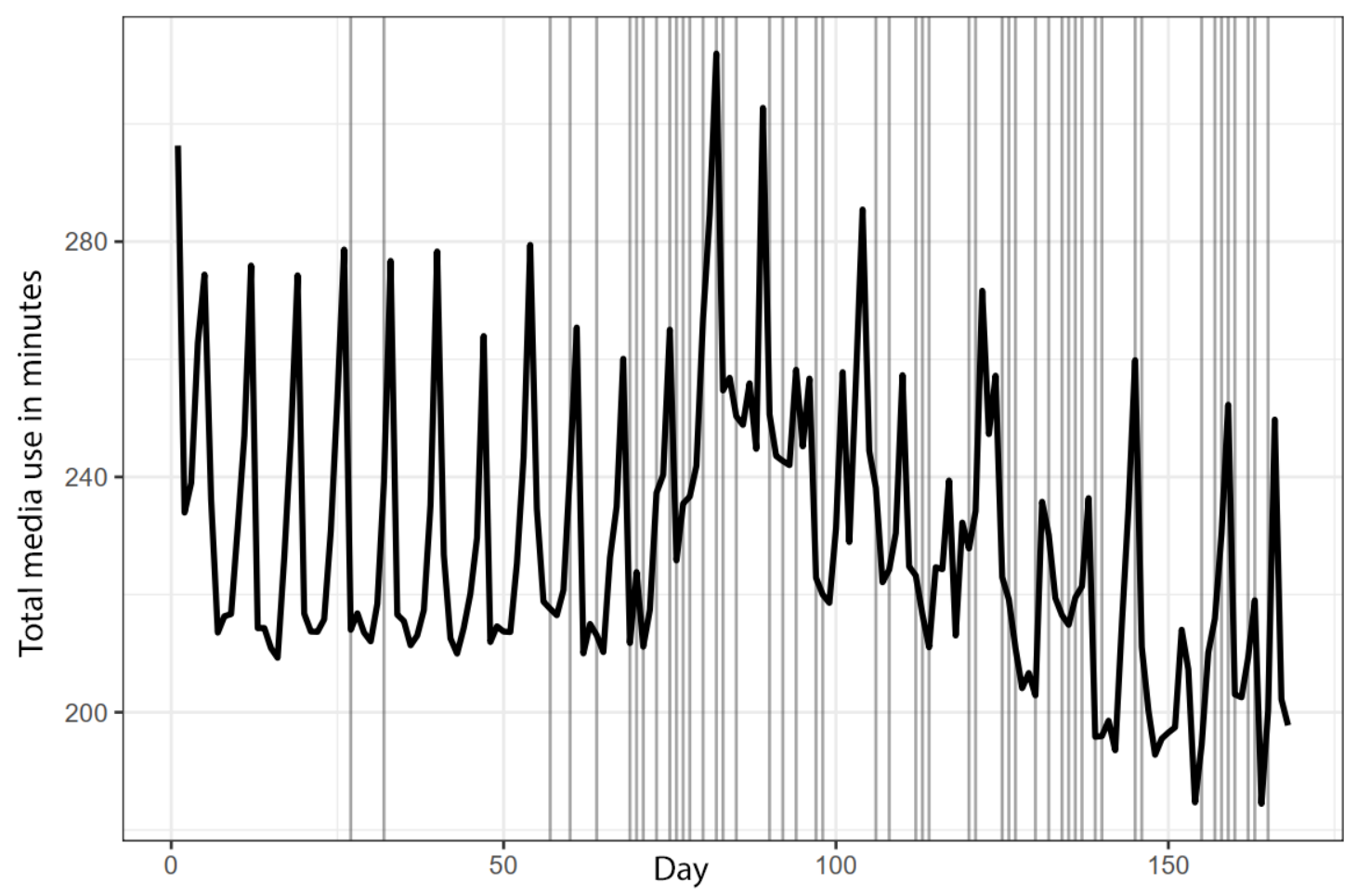

Figure 2. Total TV Use in 2020 (News and Other Programming) Note. The grey vertical lines denote the presence of a key event on that day. 


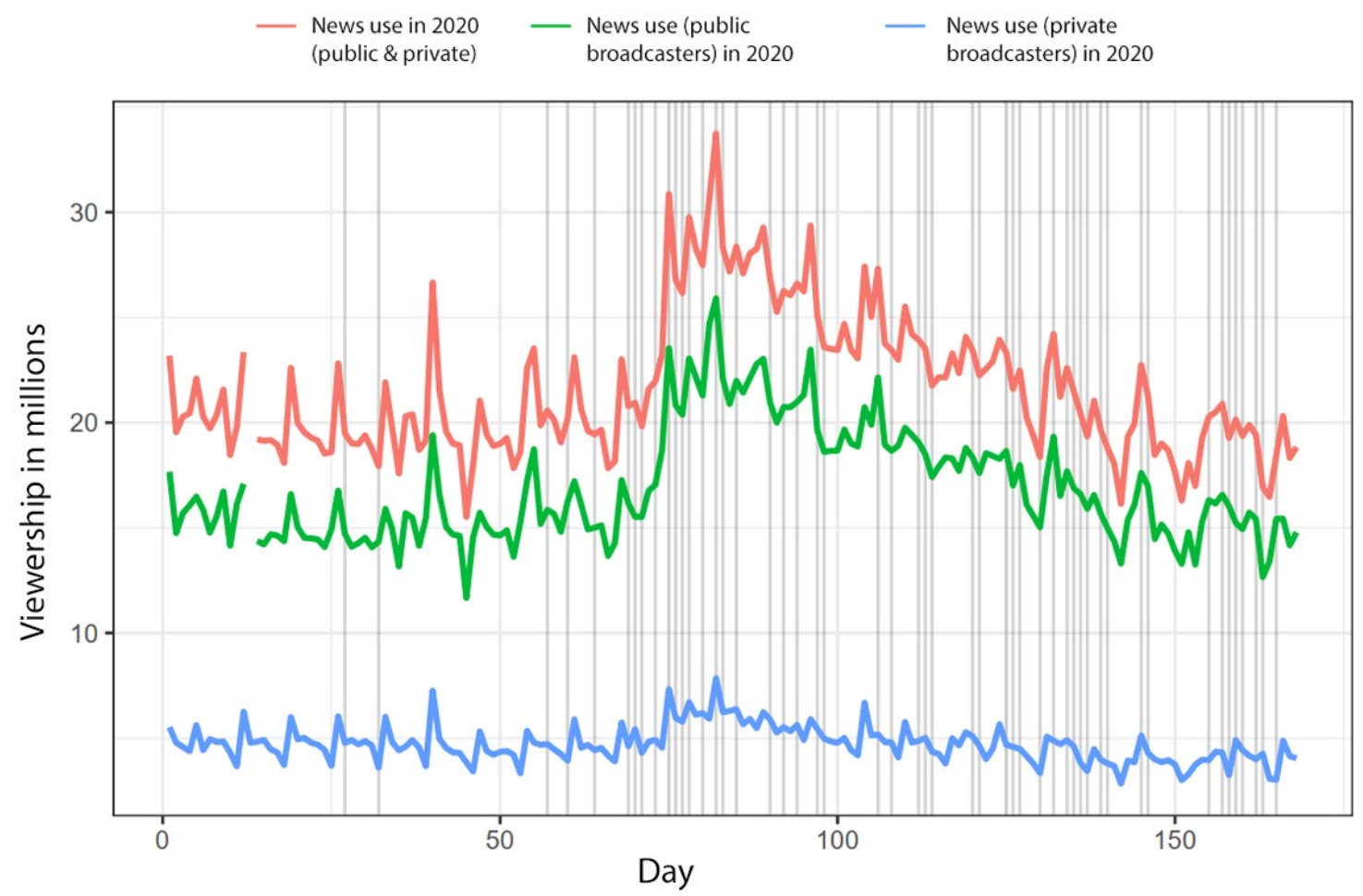

Figure 3. News Use per Broadcaster Type

Note. The grey vertical lines denote the presence of a key event on that day.

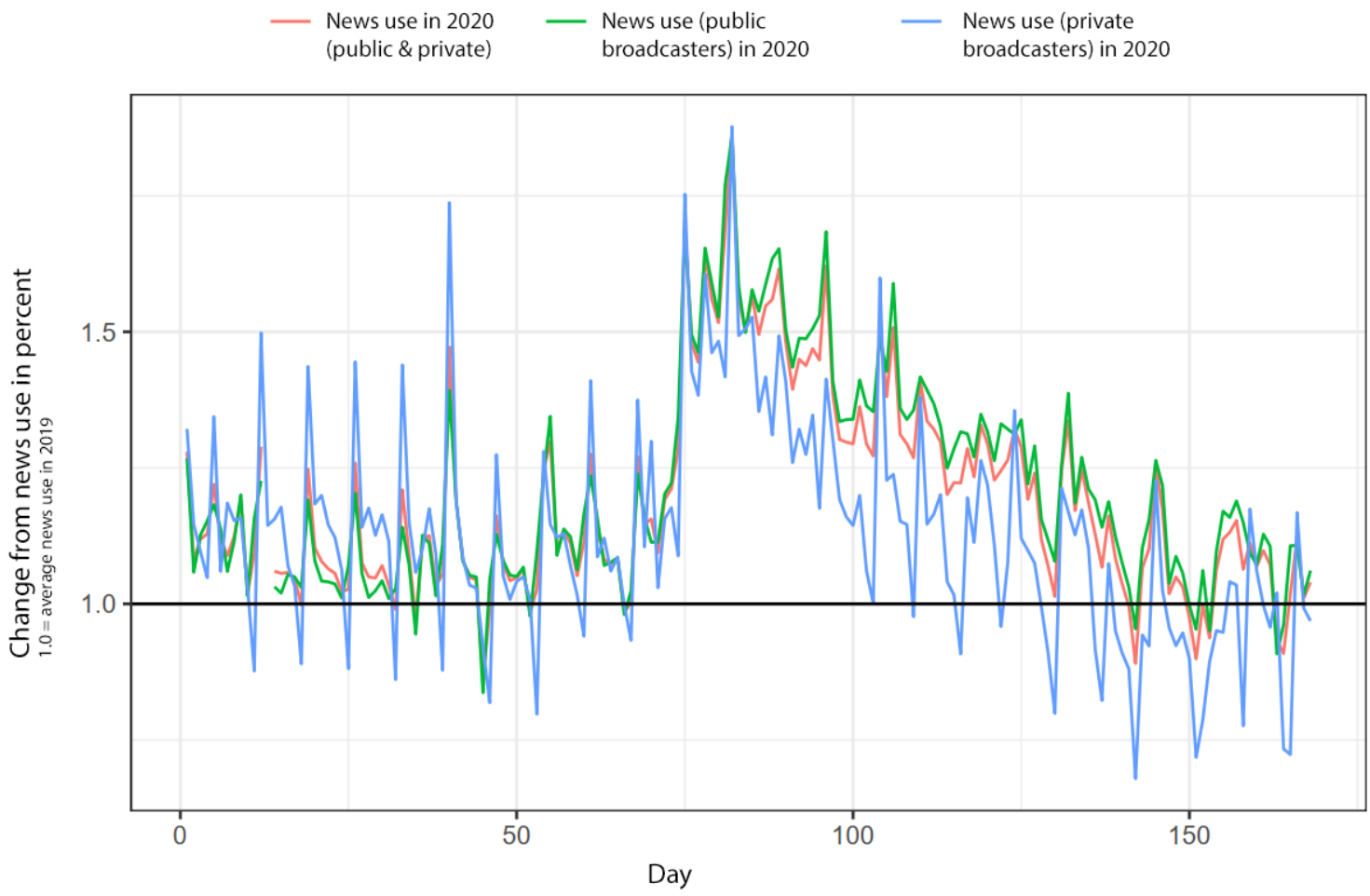

Figure 4. News Use per Broadcaster Type: Change from the Previous Year Note. The grey vertical lines denote the presence of a key event on that day. Average news use in 2019, the preceding year, was included as a baseline for comparison purposes (value $=1.0$ on the $y$-axis). 
Table 1. Generalised Additive Mixed Model Analysis Results for News Use by Broadcaster Type

\begin{tabular}{|c|c|c|c|c|c|c|c|c|c|}
\hline & \multicolumn{9}{|c|}{ Broadcaster Type } \\
\hline & \multicolumn{3}{|c|}{ Public and Private } & \multicolumn{3}{|c|}{ Public } & \multicolumn{3}{|c|}{ Private } \\
\hline & Estimate & $S E$ & $t$ & Estimate & $S E$ & $t$ & Estimate & $S E$ & $t$ \\
\hline \multirow[t]{2}{*}{ Intercept } & 21.63 & 0.19 & $113.4^{* * *}$ & 16.90 & 0.14 & $118.3^{* * *}$ & 4.72 & 0.05 & $99.16^{* * *}$ \\
\hline & $e d f$ & $\operatorname{Ref.df}$ & $F$ & $e d f$ & Ref.df & $F$ & $e d f$ & $\operatorname{Ref.df}$ & $F$ \\
\hline Total TV use & 1.00 & 1.00 & $89.15^{* * *}$ & 1.00 & 1.00 & $50.51^{* * *}$ & 1.00 & 1 & $126.94^{* * *}$ \\
\hline Disease occurrence & 3.17 & 3.17 & $33.70^{* * *}$ & 3.62 & 3.62 & $45.05^{* * *}$ & 1.00 & 1 & $9.57^{* * *}$ \\
\hline Day of the week & 4.63 & 6.00 & $9.85^{* * *}$ & 4.44 & 6.00 & $5.55^{* * *}$ & 5.53 & 6 & $26.45^{* * *}$ \\
\hline$R^{2}$ (adjusted) & & .813 & & & .819 & & & .733 & \\
\hline
\end{tabular}

Note. edf $=$ effective degrees of freedom. A value of 1.00 means that the model was estimated to be linear. Values above 1.00 denote that the model was estimated to be more winding. Ref.df = reference degrees of freedom. These predictions were made based on disease occurrence (lag $=1)$, total TV use, and day of the week. $* * * p<.001$.

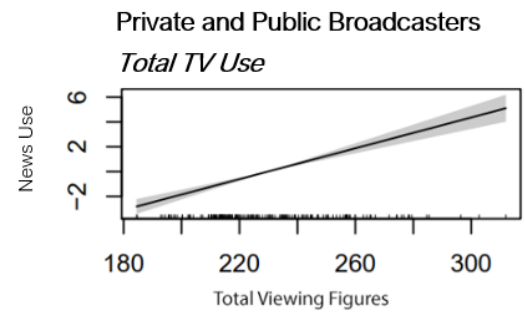

Public Broadcasters

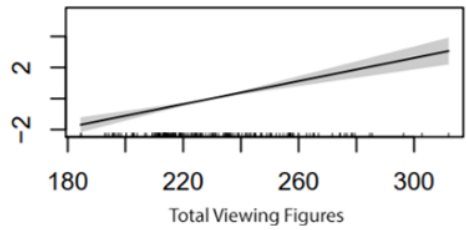

Disease Occurrence
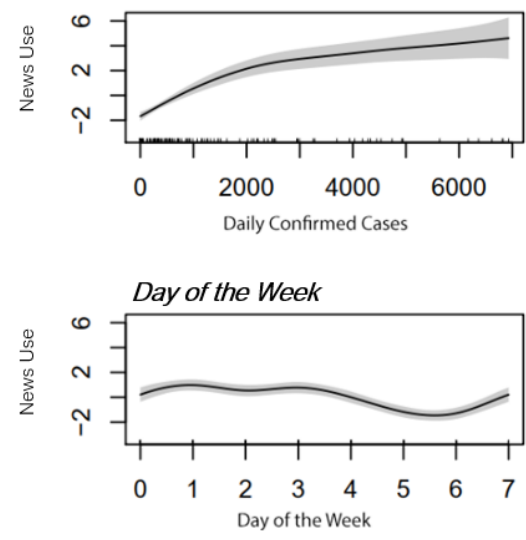
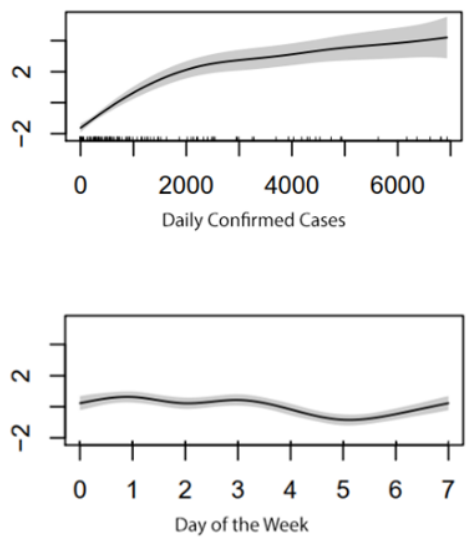

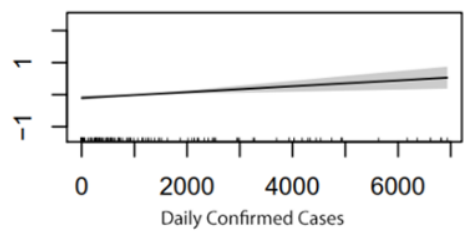

Private Broadcasters

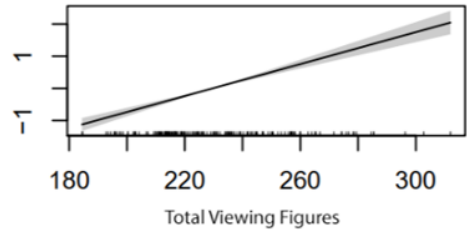

otal Viewing Figures

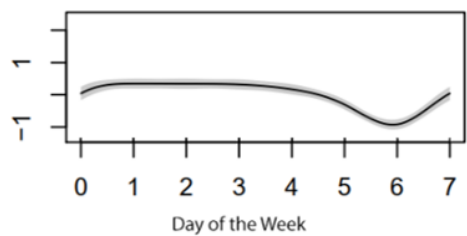

Figure 5. Plots of GAMM Smooths for Total TV Use, Disease Occurrence, and Day of the Week Note. Shading denotes confidence estimates. These predictions were made based on total TV use, disease occurrence $($ lag $=1)$, and day of the week. 

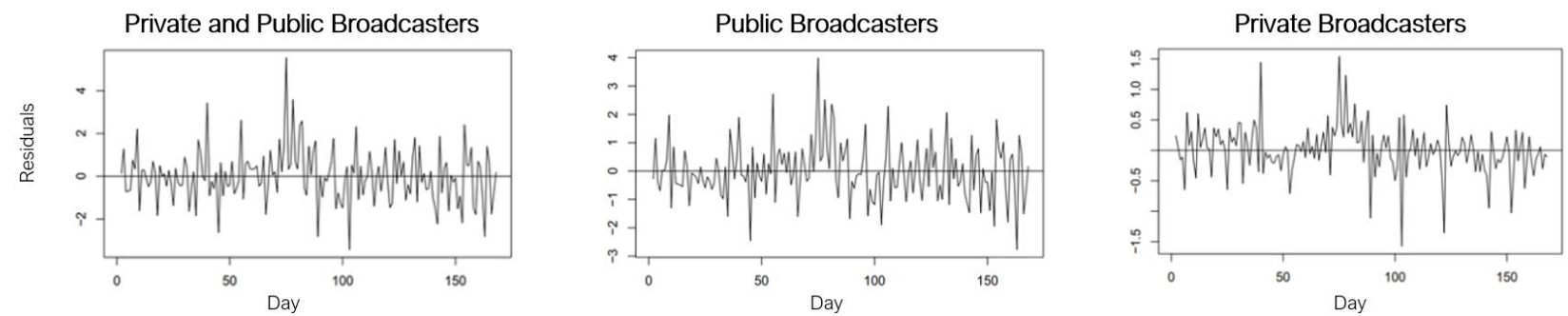

Figure 6. Residuals in Time

Partial support was found for $\mathrm{H} 2$, which stipulated that the ability of disease occurrence to predict news use would be higher for public TV stations than private ones (see Table 1 [middle and last columns] and Figure 5). Here, the analysis revealed that both types of broadcasters benefited from the pandemic (see Figure 4). Yet, this positive effect for public broadcasters-i.e., the pandemic-driven increase in the number of viewers of evening newscasts - was more enduring than what was observed for private broadcasters. Specifically, for public broadcasters, the subsequent decline in viewership was gradual. By contrast, the decline in viewership noticed for private broadcasters was faster and more abrupt. Interestingly, the effect was nonlinear for public broadcasters $(e d f=3.62)$ but linear for private broadcasters $(e d f=1.00)$.

$\mathrm{H} 3$, which posited that the ability of disease occurrence to predict news use would decrease in time, was supported. As mentioned above, a positive relationship between news use and disease occurrence was evident. Yet, the relationship was no longer linear once the threshold of 2,000 daily confirmed cases, i.e. disease occurrence, was reached ( $e d f>3$ ). Thus, about 30 days into the first wave of the pandemic, news use and disease occurrence became dissociated (i.e., a habituation effect could be noticed). From there, the rise in news use lost momentum, and the estimates of news use became less certain as the disease occurrence rose. Some differences among the broadcasters were found. Specifically, a habituation effect was observed for news use by public broadcasters but not for that issued by private broadcasters. For the latter, the decrease in news use - pointing to a habituation effect — was linear $(e d f=1)$.

H4 was supported. As anticipated, the ability of GAMM using the three independent variables (IVs) reported above to predict news use decreases as the number of key events increases. Plotting the residuals on the $y$-axis and the day in sample on the x-axis indicated that, between day 70 and day 100 - when key events accumulated - there was some noise left in the data that could not be explained by the IVs included in the model (Figure 6). This suggests that news use may be associated with key events. Notably, the data for private broadcasters included some downward spikes, suggesting the existence of key events unrelated to the pandemic. It is possible that people watched TV programming other than news, but we were unable to find specific events explaining this (e.g., major sports events).

\section{Discussion}

The current pandemic has demonstrated the disruptive nature of major outbreaks (WHO, 2007) and the importance of timely and accurate information (Liu, 2020; Voeten et al., 2009). One key finding of this study was that news use followed the curve of the disease occurrence $(\mathrm{H} 1)$, but this 
trend was more pronounced for public broadcasters' TV newscasts than for those of their private counterparts (H2). Put differently, the increase in news use was more enduring for public broadcasters.

This finding seems to suggest that the first wave of the COVID-19 pandemic in Germany prompted a need for orientation, as posed by agenda-setting theory (Matthes, 2005; McCombs, 2004) and demonstrated in earlier studies on other outbreaks (Hilton \& Hunt, 2011; Kostkova et al., 2013). It also indicates that, at the aggregate level, information seeking may have been employed as a coping mechanism (Li, 2007; Spence et al., 2008); this is in line with existing models predicting information seeking (Griffin et al., 1999; Kahlor, 2010) and recent experimental work (So et al., 2019; Tausczik et al., 2012). As this study resorted to news use as an indicator of public attention, it has also relied on theories focused on large-scale processes of information seeking and avoiding (i.e. as visible in the ups and downs in news use during a pandemic). This study could be continued with a specific examination of individuals, with a special focus on individual stress-coping theories. Indeed, people may vary in the strategies that help them cope, and this can be understood as a personality trait. For instance, some may prefer monitoring/information seeking, while blunting/information avoiding may work better for others (Miller \& Green, 1985). Future research should also assess the role of emotions - such as anxiety, uncertainty and helplessness - alongside viewer's dispositional factors (i.e., gender, age, education level, personal impact of the disease, etc.), as they might also influence information seeking.

Further, this finding underlines the importance of having high-quality news during the pandemic to disseminate updates and behavioural recommendations, exhibiting the potential to reignite discussions on journalistic quality and (health) journalism's role in society. Future studies could conduct interviews with health journalists to determine potential changes in role orientations. The finding that public newscasts benefited more from the first wave of the pandemic than private newscasts did is in line with earlier work (te Poel et al., 2021; Viehmann, 2020; Walter et al., 2012; Wong \& Sam, 2010). Future studies could seek to determine whether this is a deliberate decision, and if so, what drives it. Are assumptions about decision makers' preferences to disseminate their information key, or is this driven by trust in certain broadcasters? We can only speculate about why the effect was linear for private broadcasters. Perhaps, overall, regular viewers of RTL and Sat.1 watch less news than viewers of public broadcasters. So, a pandemic-driven peak in news use may not be sustainable. Maybe this would resemble a hay fire, in the sense that it occurs suddenly but is easily extinguished - as a habit of watching the evening newscast could not be established.

Another finding was that the linkage between disease occurrence and news use was not permanent (H3). The short-lived nature of such effects has already been established in previous studies (Bento et al., 2020; Singh et al., 2020). Specifically, 30 days into the pandemic, as the threshold of 2,000 infections was passed, news use stopped following the pattern of disease occurrence - in line with the issue-attention cycle (Downs, 1972). To us, this seems to denote the onset of a habituation effect with the "new normal," suggesting that the top level of attention to news is not sustainable, despite real-world indicators (see Ader, 1995; Arendt \& Scherr, 2019). In time, issues are bound to become "stale" (Mazur, 1998, p. 469), journalists may experience issue fatigue (Geiß, 2011), and news users may feel the burden of issue overdose (Kuhlmann et al., 
2014). In contrast, we do not see our findings as supporting the idea that news users stonewalled information (Brashers et al., 2000; Witte, 1994).

A last finding to be discussed here concerns the role of key events (H4; Brosius \& Eps, 1995). While our analysis was merely descriptive, it did appear that key events prompted a spike in news use (Downs, 1972), which has also been demonstrated in other studies (Kostkova et al., 2013; Opperhuizen \& Schouten, 2020; Vasterman \& Ruigrok, 2013). Moving forward, scholars could attempt to account for the role played by key events in more detail than was possible here. Our results suggest that the additional effort associated with this task would be rewarding.

\section{Limitations}

Like any study, the present research has some limitations. As we were interested in news use volumes, conceptualised as an indicator of public attention, we did not analyse the content of news. Accordingly, we cannot know what role the COVID-19 pandemic played in the evening newscasts. However, our informal observation as regular news users was that most topics covered in the evening news were linked to or interpreted through the prism of the pandemic. Nonetheless, a large-scale analysis of TV news may be a meaningful way to continue the research reported here. To this end, recent hands-on methodological advice for the analysis of audio-visual news can prove useful (e.g., Dan et al., 2020).

Related to the limitation outlined above, our results are correlational and cannot be interpreted causally. Thus, it is uncertain whether people considered news about the pandemic helpful in coping with anxiety. Indeed, they may have attended news for other reasons, such as perceived necessity, even though they may not have found it soothing to know more (see Geiß, 2015). Such questions seem important to us and should be addressed in future experimental studies.

Furthermore, we point out that this study only considered the linear use of TV news. However, non-linear services such as download media centres, podcasts, and on-demand services are also used as an information source (see Breunig et al., 2020). Having only relied on data regarding the use of linear TV news, the present study was thus unable to uncover whether a habituation effect could also be noticed for these types of news or not. This also goes for media use via social media.

\section{Conclusion}

The present study suggested that people use more news than usual in this context, perhaps trying to regain a sense of control over an uncertain situation. While we found no indication of information avoidance, our results suggest the onset of a habituation effect with the crisis and the emergence of information saturation. Put differently, it appears that the maximum amount of attention to news was reached early, and viewers' attention became dissociated from the disease occurrence in time. From a public health perspective, this means that increasing efforts to inform the populace during a health crisis may not necessarily lead to more attention being awarded to that information. This certainly poses challenges for public health officials, who have an interest in disseminating information able to maintain public health. 


\section{Notes}

1. The opposite is also conceivable, as suggested by Ader (1995), who found that news coverage about pollution increased as the problem became less (not more) severe. For a recent empirical study yielding results in line with this reasoning, see Arendt and Scherr (2019).

2. The following Phi values (parameter estimates) were observed: .489 for public and private news use, .449 for news use involving public broadcasters, and .325 for news use involving private broadcasters. This was accounted for in the models presented here and corrected.

3. The data reported in Table 1 and illustrated in Figure 5 suggested that news use was more likely on days on which people watched more TV (i.e., including programming other than news), but that the estimation of this linear relationship (edf $=1)$ became less precise toward the end of the spectrum, a shift suggested by the wider confidence bands in Figure 5. Furthermore, the analysis revealed that interest in news began dropping Wednesdays and reached the lowest point on Fridays (public)/Saturdays (private) before increasing again in the week. This effect was nonlinear (edf $>4$ ), and the confidence bands were similar across days of the week.

\section{Funding}

The authors received no financial support for the research, authorship, and/or publication of this article.

\section{Conflict of Interest}

The authors declared no potential conflicts of interest with respect to the research, authorship or publication of this article.

\section{References}

Ader, C. R. (1995). A longitudinal study of agenda setting for the issue of environmental protection. Journalism \& Mass Communication Quarterly, 72, 300-311. https://doi.org/10.1177/107769909507200204

Arendt, F., \& Scherr, S. (2019). Investigating an issue-attention-action cycle: A case study on the chronology of media attention, public attention, and actual vaccination behavior during the 2019 measles outbreak in Austria. Journal of Health Communication, 24(7/8), 654-662. https://doi.org/10.1080/10810730.2019.1652709

Bento, A. I., Thuy, N., Coady, W., Lozano-Rojas, F., Yong-Yeol, A., \& Simon, K. (2020). Evidence from internet search data shows information-seeking responses to news of local COVID-19 cases. Proceedings of the National Academy of Sciences of the United States of America, 117(21), 1-3. https://doi.org/10.1073/pnas.2005335117 
Brashers, D. E., Neidig, J. L., Haas, S. M., Dobbs, L. K., Cardillo, L. W., \& Russell, J. A. (2000). Communication in the management of uncertainty: The case of persons living with HIV or AIDS. Communication Monographs, 67, 63-84. https://doi.org/10.1080/03637750009376495

Breunig, C., Handel, M., \& Kessler, B. (2020). Ergebnisse der ARD/ZDF-Langzeitstudie Massenkommunikation 2020: Nutzungsmotive und Leistungsbewertungen der Medien [Results of the ARD / ZDF long-term study on mass communication 2020: Motives for use and performance ratings of the media]. Media Perspektiven, 12, 602-625. https://www.ardwerbung.de/fileadmin/user_upload/mediaperspektiven/pdf/2020/1220_Breunig_Handel_Kessler.pdf

Brosius, H.-B., \& Eps, P. (1995). Prototyping through key events: News selection in the case of violence against aliens and asylum seekers in Germany. European Journal of Communication, 10, 391-412. https://doi.org/10.1177/0267323195010003005

Dan, V., Grabe, M. E., \& Hale, B. J. (2020). Testing three measures of verbal-visual frame interplay in German news coverage of refugees and asylum seekers. International Journal of Communication, 14, 3843-3865. https://ijoc.org/index.php/ijoc/article/view/13429

Downs, A. (1972). Up and down with ecology: The issue attention cycle. Public Interest, 28, 3850.

Emmer, M., Kuhlmann, C., Vowe, G., \& Wolling, J. (2002). Der 11. September Informationsverbreitung, Medienwahl, Anschlusskommunikation [9/11: The dissemination of information, media choice, subsequent personal communication]. Media Perspektiven 4, 166177. https://www.ard-werbung.de/fileadmin/user_upload/media-perspektiven/pdf/2002/042002_Emmer.pdf

Gehrke, G., \& Hohlfeld, R. (1994). Themenstruktur im dualen Fernsehsystem. Eine exemplarische Untersuchung von ARD, ZDF, RTL und SAT.1 [Topic structure in the dual television system. An exemplary study of ARD, ZDF, RTL and SAT.1]. Media Perspektiven, $5,241-251$.

Geiß, S. (2011). Patterns of relationships between issues: An analysis of German prestige newspapers. International Journal of Public Opinion Research, 23(3), 265-286. https://doi.org/10.1093/ijpor/edq050

Geiß, S. (2015). Die Aufmerksamkeitsspanne der Öffentlichkeit: Eine Studie zur Dauer und Intensität von Meinungsbildungsprozessen. Nomos.

Griffin, R. J., Dunwoody, S., \& Neuwirth, K. (1999). Proposed model of the relationship of risk information seeking and processing to the development of preventive behaviors.

Environmental Research, 80(2), S230-S245. https://doi.org/10.1006/enrs.1998.3940

Hawkins, V. (2011). Media selectivity and the other side of the CNN effect: The consequences of not paying attention to conflict. Media, War \& Conflict, 4(1), 55-68.

https://doi.org/10.1177/1750635210396126

Hilton, S., \& Hunt, K. (2011). UK newspapers' representations of the 2009-10 outbreak of swine flu: One health scare not over-hyped by the media? Journal of Epidemiology and Community Health, 65(10), 941-946. https://doi.org/10.1136/jech.2010.119875

Hölig, S., \& Hasebrink, U. (2019). Reuters Institute digital news report 2019. Ergebnisse für Deutschland [Results from Germany]. https://www.hans-bredowinstitut.de/uploads/media/default/cms/media/os943xm_AP47_RDNR19_Deutschland.pdf 
Kahlor, L. (2010). PRISM: A planned risk information seeking model. Health Communication, 25(4), 345-356. https://doi.org/10.1080/10410231003775172

Klingler, W., \& Turecek, I. (2019). Medienzeitbudgets und Tagesablaufverhalten [Media time budgets and daily routines]. Media Perspektiven, 2, 98-107. https://www.ard-

werbung.de/fileadmin/user_upload/media-perspektiven/pdf/2016/02-

2016_Klingler_Turecek.pdf

Köhler, G. (2006). Qualität von Fernsehnachrichten aus Zuschauerperspektive [Quality of television news from viewers 'perspective]. Freie Universität Berlin.

Kostkova, P., Fowler, D., Wiseman, S., \& Weinberg, J. R. (2013). Major infection events over 5 years: How is media coverage influencing online information needs of health care professionals and the public? Journal of Medical Internet Research, 15(7), Article: e107. https://doi.org/10.2196/jmir.2146

Krupp, M. (2020). Media Perspektiven Basisdaten: Daten zur Mediensituation in Deutschland [Media perspectives basic data: Data on the media situation in Germany]. https://www.ardwerbung.de/fileadmin/user_upload/mediaperspektiven/Basisdaten/Basisdaten_2020_Internet_mit_Verknuepfung.pdf

Kuhlmann, C., Schumann, C., \& Wolling, J. (2014). "Ich will davon nichts mehr sehen und hören!" Exploration des Phänomens Themenverdrossenheit. Medien \& Kommunikationswissenschaft, 62(1), 5-24. https://www.nomos-elibrary.de/10.5771/1615634x-2014-1-5/ich-will-davon-nichts-mehr-sehen-und-hoeren-exploration-des-phaenomensthemenverdrossenheit-jahrgang-62-2014-heft-1

Li, X. (2007). Stages of a crisis and media frames and functions: U.S. television coverage of the 9/11 incident during the first 24 hours. Journal of Broadcasting \& Electronic Media, 51(4), 670-687. https://doi.org/10.1080/08838150701626578

Liu, P. L. (2020). COVID-19 Information seeking on digital media and preventive behaviors: The mediation role of worry. Cyberpsychology, Behavior and Social Networking, 23(10), 677-682. https://doi.org/10.1089/cyber.2020.0250

Matthes, J. (2005). The need for orientation towards news media: Revising and validating a classic concept. International Journal of Public Opinion Research, 18(4), 422-444. https://doi.org/10.1093/ijpor/edh118

Mazur, A. (1998). Global environmental change in the news. 1987-90 vs. 1992-96. International Sociology, 13(4), 457-472. https://doi.org/10.1177/026858098013004003

McCombs, M. E. (2004). Setting the agenda: The mass media and public opinion. Blackwell.

Miller, S. M., \& Green, M. L. (1985). Coping with stress and frustration. In M. Lewis \& C. Saarni (Eds.), The Socialization of Emotions (pp. 263-314). Springer.

Opperhuizen, A. E., \& Schouten, K. (2020). Dynamics and tipping point of issue attention in newspapers: quantitative and qualitative content analysis at sentence level in a longitudinal study using supervised machine learning and big data. Quality \& Quantity. https://doi.org/10.1007/s11135-020-00992-w

Seeger, M. (2002). CDC funding for crisis communication research highlighted at NCA convention. Spectra, 38(2), 7. 
Singh, L., Bansal, S., Bode, L., Budak, C., Chi, G., Kawintiranon, K., Padden, C., Vanarsdall, R., Vraga, E., \& Wang, Y. (2020). A first look at COVID-19 information and misinformation sharing on Twitter. Cornell University.

So, J., Kuang, K., \& Cho, H. (2019). Information seeking upon exposure to risk messages: Predictors, outcomes, and mediating roles of health information seeking. Communication Research, 46(5), 663-687. https://doi.org/10.1177/0093650216679536

Spence, P. R., Lachlan, K. A., \& Burke, J. M. (2008). Disaster preparation, media use, and information seeking: Patterns across Katrina evacuees and lessons learned for disaster communication. Journal of Emergency Management, 6(2), 11-23. https://doi.org/10.5055/jem.2008.0009

Tausczik, Y., Faasse, K., Pennebaker, J. W., \& Petrie, K. J. (2012). Public anxiety and information seeking following the H1N1 outbreak. Health Communication, 27(2), 179-185. https://doi.org/10.1080/10410236.2011.571759

te Poel, F., Linn, A. J., Baumgartner, S. E., van Dijk, L., \& Smit, E. S. (2021). Sick for Information?: Information Needs and Media Use of the Dutch Public During the Covid-19 Pandemic. European Journal of Health Communication, 2(3), 24-43. https://doi.org/10.47368/ejhc.2021.302

Ungar, S. (1992). The rise and (relative) decline of global warming as a social problem. The Sociological Quarterly, 33, 483-501. https://doi.org/10.1111/j.1533-8525.1992.tb00139.x

Ungar, S. (2000). Knowledge, ignorance and the popular culture: Climate change versus the ozone hole. Public Understanding of Science, 9, 297-312. https://doi.org/10.1088/0963$6625 / 9 / 3 / 306$

Vasterman, P. L. M. (2005). Media-hype: Self-reinforcing news waves, journalistic standards and the construction of social problems. European Journal of Communication, 20(4), 508530. https://doi.org/10.1177/0267323105058254

Vasterman, P. L. M., \& Ruigrok, N. (2013). Pandemic alarm in the Dutch media: Media coverage of the 2009 influenza A (H1N1) pandemic and the role of the expert sources. European Journal of Communication, 28(4), 436-453. https://doi.org/10.1177/0267323113486235

Viehmann, C. (2020). Deutschland in Zeiten der Corona-Krise: Gut informiert und mit gestärktem Gemeinschaftsgefühl in eine unsichere Zukunft? [Press release]. https://www.unimainz.de/presse/aktuel1/11144_DEU_HTML.php

Voeten, H. A. C. M., de Zwart, O., Veldhuijzen, I. K., Yuen, C., Jiang, X., Elam, G., Abraham, T., \& Brug, J. (2009). Sources of information and health beliefs related to SARS and avian influenza among Chinese communities in the United Kingdom and the Netherlands, compared to the general population in these countries. International Journal of Behavioral Medicine, 16(1), 49-57. https://doi.org/10.1007/s12529-008-9006-4

Walter, D., Bohmer, M., Reiter, S., Krause, G., \& Wichmann, O. (2012). Risk perception and information-seeking behaviour during the 2009/10 influenza A(H1N1)pdm09 pandemic in Germany. Euro surveillance: bulletin Europeen sur les maladies transmissibles = European Communicable Disease Bulletin, 17(13). https://doi.org/10.2807/ese.17.13.20131-en

Witte, K. (1994). Fear control and danger control: A test of the extended parallel process model (EPPM). Communication Monographs, 61, 113-132. https://doi.org/10.1080/03637759409376328 
Wong, L. P., \& Sam, I. C. (2010). Public sources of information and information needs for pandemic influenza A (H1N1). Journal of Community Health, 35(6), 676-682. https://doi.org/10.1007/s10900-010-9271-4

World Health Organization. (2007). Risk reduction and emergency preparedness. WHO six-year strategy of the health sector and community capacity development. WHO.

\section{Author Contributions}

Conceptualization (main idea, theory): Viorela Dan \& Hans-Bernd Brosius

Funding acquisition: N/A

Project administration: Viorela Dan \& Hans-Bernd Brosius

Methodology (design, operationalization): Viorela Dan \& Hans-Bernd Brosius

Data collection: publicly available data; Nataliia Vysotska provided research assistance on key events

Data analysis: Viorela Dan \& Hans-Bernd Brosius, with assistance from Veronika Kronseder and André Klima

Writing - original draft: Viorela Dan

Writing - review \& editing: Viorela Dan

\section{Author Biographies}

Viorela Dan, Dr. phil., is Akademische Rätin (postdoctoral researcher) at the Department of Media and Communication of the LMU Munich. Her most recent research focuses on fact checking and the effective correction of misinformation and disinformation. She is the author of Integrative Framing Analysis. Framing Health Through Words and Visuals (Routledge, 2018).

Hans-Bernd Brosius is Professor of Empirical Communication Research at the Department of Media and Communication of the LMU Munich. He studied Psychology and Medicine at the University of Münster. After receiving his doctorate in 1983 he worked as a project assistant and later as an assistant professor at Johannes Gutenberg University Mainz, where he habilitated with a study on the reception of news in 1994. 